\title{
Developing a frame of reference for ex-ante IT/IS investment evaluation
}

\author{
Z Irani $^{1{ }^{1 *}}$ and PED Love ${ }^{2}$ \\ ${ }^{1}$ Information Systems Evaluation and Integration Group (ISEIG), Department of Information Systems and Computing, Brunel \\ University, Uxbridge, UK; and ${ }^{2}$ School of Management Information Systems, Edith Cowan University Churchlands Campus, \\ Perth, Australia
}

\begin{abstract}
Investment appraisal techniques are an integral part of many traditional capital budgeting processes. However, the adoption of Information Systems (IS) and the development of resulting infrastructures are being increasingly viewed on the basis of consumption. Consequently, decision-makers are now moving away from the confines of rigid capital budgeting processes, which have traditionally compared IS with non-ISrelated investments. With this in mind, the authors seek to dissect investment appraisal from the broader capital budgeting process to allow a deeper understanding of the mechanics involved with IS justification. This analysis presents conflicting perspectives surrounding the scope and sensitivity of traditional appraisal methods. In contributing to this debate, the authors present taxonomies of IS benefit types and associated natures, and discuss the resulting implications of using traditional appraisal techniques during the IS planning and decision-making process. A frame of reference that can be used to navigate through the variety of appraisal methods available to decision-makers is presented and discussed. Taxonomies of appraisal techniques that are classified by their respective characteristics are also presented. Perspectives surrounding the degree of involvement that financial appraisal should play during decision making and the limitations surrounding investment appraisal techniques are identified.
\end{abstract}

\section{Introduction}

Organisational reliance on Information Technology (IT)/Information Systems (IS) continues to grow and is in part reflected by the large sums of money being spent on its adoption. The World Information Technology Services Alliance (WITSA, 2000) reported that the global information and communications industry surpassed the US\$2 trillion mark in 2000, and predicts it reaching the US\$3 trillion level by 2004. It therefore appears reasonable to suggest that there may be an increased reliance on capital budgeting as a management process for allocating finances to the implementation of new technology. However, this is often not the case, with the adoption of IT/IS increasingly being viewed by managers as a process of consumption rather than capital expenditure, therefore, often placing the justification of IT/IS outside the confines of traditional budgeting processes, albeit with varying degrees of reliance on investment appraisal techniques.

The scope and limitations of investment appraisal techniques are widely reported in the accounting and finance literature (eg Sundem \& Geijsbeck, 1978; Scap-

\footnotetext{
*Correspondence: Z Irani, Information Systems Evaluation and Integration Group (ISEIG), Department of Information Systems and Computing, Brunel University Uxbridge, Middlesex, UB8 3PH, UK E-mail: zhair.irani@brunel.ac.uk
}

ens \& Sales, 1981; Gurnami, 1984; Lumby, 1993). In addition, various empirical studies reporting the use of appraisal techniques for the purpose of ex-ante investment evaluation have also been discussed in the IS literature (eg Lefley \& Sarkis 1997; Ballantine \& Stray, 1998, 1999<aq1>; Arribas \& Inchusta 1999; Anandarajan \& Wen 1999). However, Small \& Chen (1995) report that large numbers of companies find the evaluation process confusing and without consensus on what constitutes meaningful appraisal. Such opinions are not isolated and have also been echoed by Farbey et al (1993), Smithson \& Hirschheim (1998), Remenyi et al (2000) and Irani \& Love (2001). It is in exploring and then classifying the scope and sensitivity of the plethora of appraisal techniques available to decision-makers where this paper will make a contribution to the normative literature.

The paper commences by describing the stages involved in capital budgeting and in doing so, allowing the reader to position investment appraisal within the broader budgeting process. The purposes of investment appraisal together with the objectives that it serves are then highlighted. This is followed by a discussion about the conflicting perspectives and limitations associated with using traditional appraisal methods. A 'frame of reference' that can be used to navigate through the variety of appraisal methods available to decision-makers is presented and discussed. Taxonomies of appraisal 


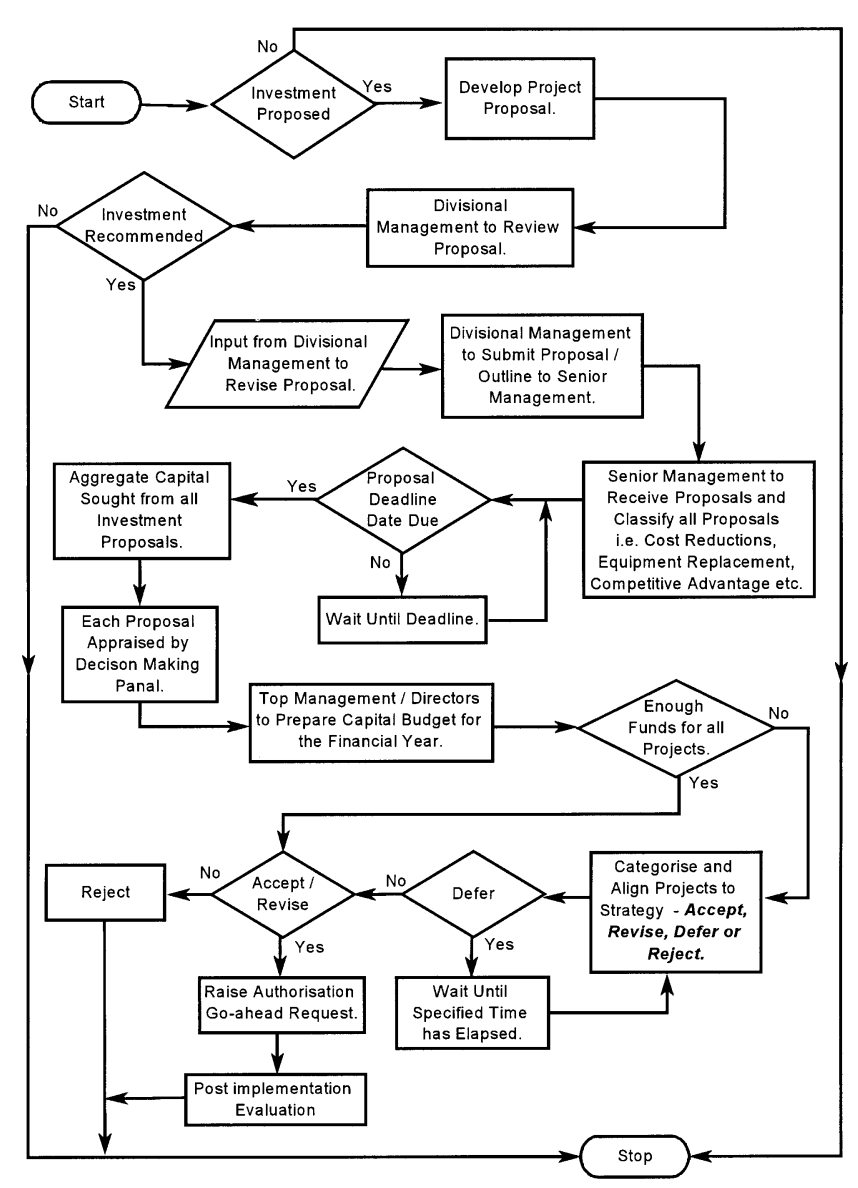

Figure 1 Capital budgeting process.

techniques that are classified by their respective characteristics are also presented. Perspectives surrounding the degree of involvement that financial appraisal should play during decision making and the limitations surrounding investment appraisal techniques are identified.

\section{Capital budgeting: management decision making}

Butler et al (1993) describe capital budgeting as a process whereby organisational resources are allocated in the anticipation of future gains. Slagmulder et al (1995) describe capital budgeting within many large organisations, proceeding from the bottom-up. That is, companies are assumed to let investment proposals bubble-up from grass-root levels for review by divisional management. Then, this may be followed by a more detailed analysis at a senior management level. Anthony et al (1984) identify the following steps as integral to capital budgeting, with the authors summarising these largely bureaucratic stages and presenting them in Figure 1.

- project innovator(s) identify a project need, which is detailed within an investment proposal;

- divisional management reviews the proposal and submits recommendations; along with a project outline, to senior management;

- investment proposals are then classified and prioritised under appropriate headings; cost reductions, equipment replacement, competitive advantage, etc;

- investment proposals from each department are then aggregated into a capital budget which is usually prepared once a year;

- individual projects are then appraised, and revised if necessary, based on the comments from the decision-makers;

- directors prepare a capital budget, by appraising individual projects as well as identifying the total amount of funds requested;

- projects are then revised, deleted, or deferred, based on the budget available;

- authorisation requests are then prepared for the successful project(s); and

- post-implementation audits are carried out once the system has been operational, to identify the level of cost and benefit realisation.

\section{Positioning investment appraisal within the capital budgeting process}

One of the most widely criticised activities conducted by accountants during capital budgeting concerns their use of investment appraisal techniques (Meredith \& Suresh, 1986; Dugdale \& Jones, 1995). Nonetheless, it is worthwhile to consider the reasons why companies appraise IT/IS investments. These include, but are not limited to:

- enable different projects to be compared;

- act as a mechanism to rank projects in terms of organisational priorities;

- justify investment requests by management;

- act as a control mechanism over expenditure, benefits and the development and implementation of projects; and

- act as a means of providing a framework that facilitates organisational learning.

Along similar lines, Ginzberg \& Zmud (1988) and Angell \& Smithson (1991) have identified other objectives of IT/IS investment appraisal. These include:

- a process for gaining information that feeds projects planning and resource allocation;

- as a benchmarking process to ensure the system continues to perform well against planned deliverables; and

- to ensure decisions concerning expansion, improvement, or the postponement of projects can be taken. All of the above reasons place investment appraisal in a positive and constructive light and portray it as an important part of the decision-making process. However, Primrose (1991) identifies the manufacturing industry's perception of investment appraisal as a budgetary pro- 
cess that gives a final 'yes' or 'no'- 'pass' or 'fail' verdict on the success of a projects proposal. As a result, many managers view project appraisal as a financial hurdle that has to be overcome and not as a technique for evaluating the project's worth. This has significant implications during the preparation of a project's proposal, where managers spend much time and effort investigating its technical aspects and thus become committed to the belief that the project is essential. Consequently, members of the evaluation team (decision-makers) may be easily susceptible to persuasion by vendors and consultants and be prepared to accept untypical demonstrations. Hence, decision-makers may focus their efforts on trying to identify and estimate significant business benefits from making the IT/IS investment at the expense of overlooking the full cost and risk implications of the investment. Drummond (1996) describes this management trait as escalation theory, whereby managers are overwhelmed by the momentum of the project and as a result need to secure funding.

\section{Limitations of investment appraisal techniques}

Farbey et al (1993) argue that the use of traditional IT/IS appraisal methods are inappropriate for the purposes of evaluation. In describing this, it would appear that although capital acquisition policies based on the use of traditional appraisal techniques have worked well for decisions concerning manufacturing capital equipment, such procedures are regarded inappropriate for the appraisal of IT/IS applications that often have many qualitative project implications. The reason for this is that there is a difference in the portfolio of benefits associated with strategic IT/IS, which often consist of significant intangible and non-financial benefits (Irani et al, 1998; Love \& Irani, 2001). This is further complicated by the inability of traditional appraisal techniques to accommodate the indirect costs associated with IT/IS (Irani et al, < <aq2>02001). Hence, the inability of such methods to address the changing portfolio of IT/ISrelated benefits (increasingly qualitative) and costs (indirect) might be considered contributing factors towards the slow adoption of IT/IS, although there is limited empirical research that has been undertaken to support this conjecture.

Farbey et al (1992) reported the experience of companies using traditional approaches to project justification, and identified the uncertainty of how to measure the full impact of their IT/IS investments, in particular, non-financial and intangible implications. Similarly, Hochstrasser (1992) suggests that those justification processes based on standard accounting methods simply do not work in today's IT/IS environment. Maskell (1991) explores this by suggesting that traditional modes of investment appraisal are unable to capture many of the softer benefits that IT/IS yields. Yet, Parker \& Benson (1989) offer an alternative view, and report that many Chief Executive Officers (CEOs) are uncomfortable with using the available set of IT/IS appraisal tools and techniques. They suggest that such methods lack the precision and presentation of results in the form that CEOs expect. Traditional appraisal techniques as reported as being imperfect and furthermore many organisations feel uneasy or even dissatisfied with their use. Interestingly, Bannister \& Remenyi (2000) describe that as the limitations of investment appraisal methods become more evident, decision-makers are falling back on 'gut feel' and other non-formal/rigorous ways of making decisions.

Proctor \& Canada (1992) and more recently Irani et al (1999a) have expressed their concern over the generic nature of traditional investment appraisal methods. Indeed, the premise of such methods is that they act as generic appraisal tools, which are used to assess the full implications of all types of investment proposals. However this brief may be considered too ambitious, largely due to the wide range of interacting socio-technical factors (Serafeimidis \& Smithson 2000; Irani \& Love, 2001). Farbey et al (1993) claim that the search for a single appraisal technique that addresses all project considerations is fraught with difficulty. The reason for this is that investments in IT/IS are aggregates of complexity and notably different from each other. The circumstances where an appraisal technique would be applied is so wide and varied that no single method would appear able to cope with the complexities associated with decision making. Clearly, each investment project displays its own unique characteristics and offers a diverse range of benefits and costs. Conversely, each appraisal technique displays its own range of characteristics, which distinguish them from one another (Farbey et al, 1994). Furthermore, every method has its own set of respective limitation (Irani et al, 1997a). Therefore, the development of an all-embracing generic appraisal technique that takes account of the wide variety of IT/IS-related implications may be considered too rigid and complex for use by decision-makers.

\section{Information system planning levels: strategic, tactical and operational}

It is proffered that the level and nature of those benefits identified and discussed during ex-ante evaluation may depend on the position of manager seeking the benefits. In support of this, Anthony (1965) proposed the following management levels:

- strategic;

- tactical; and

- operational.

These levels are related to the traditional levels of top 


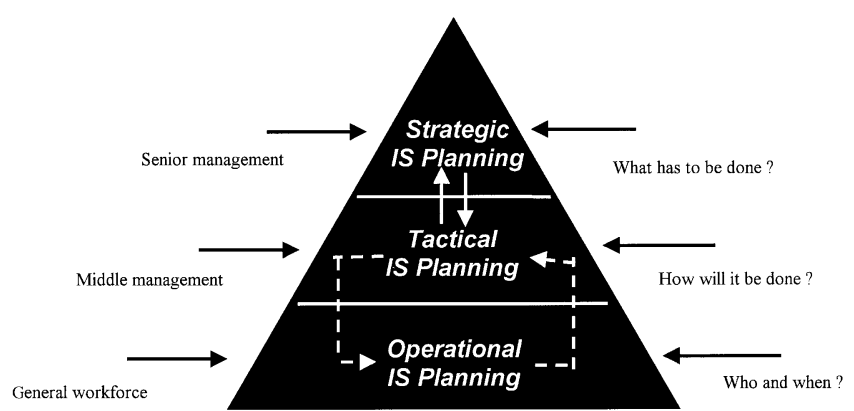

Figure 2 Level of IS planning and evaluation (adapted from Wysocki and Young, 1989).

\section{Tactical characteristics} supervisory management. It is perhaps not surprising that Wysocki \& Young (1989) describe IS planning and evaluation as a process that takes place at the aforementioned distinct levels (Figure 2). These levels address the issue of 'what managers do' by emphasising that management consists of planning and control activities, which are determined by the manager's level in the organisation. For example, a simple way of looking at strategic planning is that it is concerned with 'what will be done within the organisation', at a tactical level, with 'how it will be done'; and then at an operational level, with 'who will do it and when' (Figure 2).

Investment decisions are based on expectations. With this in mind, Harris (1996) explains that judgements, intuition, creativity, ideas, opinions and experience often guide such decisions. Yet, such factors are often grounded by management positions and corresponding levels within an organisation (Irani et al, 1999b). Thus, it is not unrealistic to suggest levels of IS planning display strategic, tactical and operational characteristics.

\section{Strategic characteristics}

Strategic planning entails the participation of the organisation in a business-planning exercise. That is, managers may not only be involved in developing specific systems to implement corporate strategy, but also be expected to participate in the actual development of the strategy. In addition, strategic planning might involve monitoring and supporting improvements to the strategic performance of the organisation and its supply chain (eg the development of inter-organisational systems for supply chain management and IS integration). The strategic decisions, which are often taken by senior management, may be uncertain and therefore risky. Such investment opportunity proposals may respond or be based on opportunities, often looking far into the future, and may be motivated by the need to improve competitiveness. These proposals may need long-term planning for implementation, and are likely to be made by senior managers.
Once the goals and objectives of the company and IS project are clearly understood and priorities established, it becomes the responsibility of middle management to decide on how these goals and objectives are accomplished. These managers develop and evaluate short-term and medium-range plans and budgets, and specify the policies, procedures and objectives for the sub-units of the company. Tactical plans in addition to strategic planning involves the acquisition of resources, but largely involves their allocation to monitor the performance of organisational sub-units, such as departments, divisions and other work groups/projects. Tactical decisions tend to be planned on the resources available and/or affordable so that the objectives set by strategic decisions are met. Essentially, middle managers are concerned with the allocation of resources to support strategic goals. An example could be ensuring targets for the year are met within their allocated budget, with such targets being supported through the adoption of a technology.

\section{Operational characteristics}

Operational decisions are those most frequently made and may be financially motivated. Line managers or even operational employees may take these decisions. Essentially, it involves monitoring the resources used at a project level, and consists of supervising, controlling, and variance reporting of the 'who and when' aspects of on-going operations or projects. Line managers may also direct the use of resources, advise on the performance of tasks that are 'in-line' with established procedures and determine budgets and schedules for work groups. Since there is a structured nature to this type of decision making, it can even be made by a computer, for example, the use of a spreadsheet to assess cash flow fluctuations, following improved throughput production flow.

\section{Linking information system planning to IT/IS benefit levels}

Earlier sections suggest that in addition to management having difficulty in quantifying many IT/IS benefits, such benefits occur at different organisational levels. Therefore, an interesting proposition appears to unfold, which links IS planning to IT/IS benefit levels and therefore supports ex-ante evaluation. Figure 3 shows that IS benefits can be mapped on to corresponding planning levels; strategic, tactical and operational. Furthermore, such benefits are considered to display different natures.

However, the notion of benefit classification is not new, with Tayyari \& Kroll (1990) having divided those benefits achievable through the adoption of new technology into two categories, namely direct benefits and intangible benefits. Demmel \& Askin (1992) also classi- 


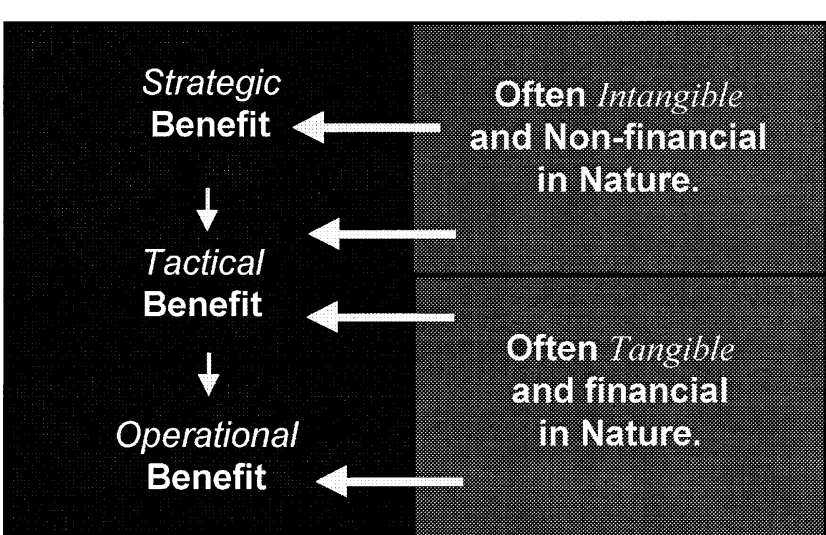

Figure 3 Planning and benefit levels with their nature of benefits.

fied IT/IS benefits and proposed the following three categories: strategic, tactical and pecuniary. Peters (1994) suggested that benefits of IT/IS typically fall into the classifications of enhanced productivity, business expansion and risk minimisation. Regardless of the preferred categorisation discussed, Chen \& Small (1994) argue that investment justification should include a consideration of all benefits achievable through investing in the new technology. They go on to suggest rigorous investment justification should only be attempted after a company has identified those benefits that are required, and following a consideration of the infrastructural changes that are needed to support the achievement of the required benefits. However, it is not just benefit management that is important within the context of IT/IS life-cycle evaluation, as the need for a robust cost identification and management has also been identified (eg Ezingeard et al, 1999; Khalifa et al, 1999; Irani et al, 2000, Irani \& Love, 2000). Hence, it has become clear that IS comprise of benefits and cost portfolios, which need consideration during the appraisal process (exante). Yet this leaves decision-makers with a problem, that is, navigating through the many types of appraisal techniques available, and thus establishing the need for an appropriate mechanism for ex-ante investment evaluation.

\section{Towards a frame of reference: taxonomy of appraisal techniques}

Ballantine \& Stray (1998) offer empirical evidence that suggests accountants are slow, reluctant, or even refusing to adopt more sophisticated appraisal techniques/management guidelines, which claim to address many of the limitations inherent in traditional appraisal approaches. However, the vast array of appraisal techniques available leaves many decisionmakers with the quandary of deciding which method(s) to use, if any. Dugdale \& Jones (1995) claim that conventional appraisal techniques mitigate against the adop- tion of new technology, and that companies using these approaches may be restricting themselves in their ability to compete in world markets. Regardless, the use of these techniques continues, even though the method adopted for selecting evaluation criteria, for example, payback periods or discount/hurdle rates, have been identified as demonstrating short-termism and the misallocation of resources. As a result, such methods would appear counterproductive to those IT/IS deployments that seek long-term flexibility and integration. The inability to include many benefits and costs during $e x$ ante evaluation is seen as proof in the failure of traditional investment appraisal techniques, therefore, prompting management to consider the broader analysis of appraisal techniques and thus, supporting the development of a taxonomy that can be used as a frame of reference.

Although fallible investment appraisal techniques are critical elements in management's control systems. The rationale that underpins the use of these methods is that they are designed to channel capital investments in the desired direction. Consequently, companies place considerable importance on investment appraisal. Indeed, Renkema \& Berghout (1997) identified with no particular structure, a comprehensive list of over 65 appraisal techniques, all claiming to contribute towards the decision-making process. Regardless of such a wide choice, more complicated methods and prescriptive guidelines continue to appear. However, much literature suggests the inappropriateness of these techniques (Farbey et al, 1993), while others, such as Ballantine \& Stray (1998) report their application. To enable senior managers to understand the differences, characteristics and limitations that are inherent within many modes of appraisal, the authors have built on the work of Naik \& Chakravarty (1992) to develop a selection of appraisal techniques within taxonomies (Figure 4). The taxonomies sub-classify methods into:

(1) economic ratio appraisal;

(2) economic discounting appraisal;

(3) strategic appraisal;

(4) analytic portfolio appraisal;

(5) integrated appraisal;

(6) other analytic appraisal.

In the classification presented in Figure 4, economic appraisal techniques appear to be based on the assignment of cash values, to tangible benefits and costs but largely ignore project, or event risk, non-financial and intangible IT/IS implications. However, such project implications (intangibility and risk) may be addressed in part through the manipulation of the discount/hurdle rate, or payback period, although its use often remains subjective. These modified approaches to traditional financial appraisal are often referred to as hybrid but, nevertheless, remain judgmental in nature.

Strategic approaches to investment appraisal combine 


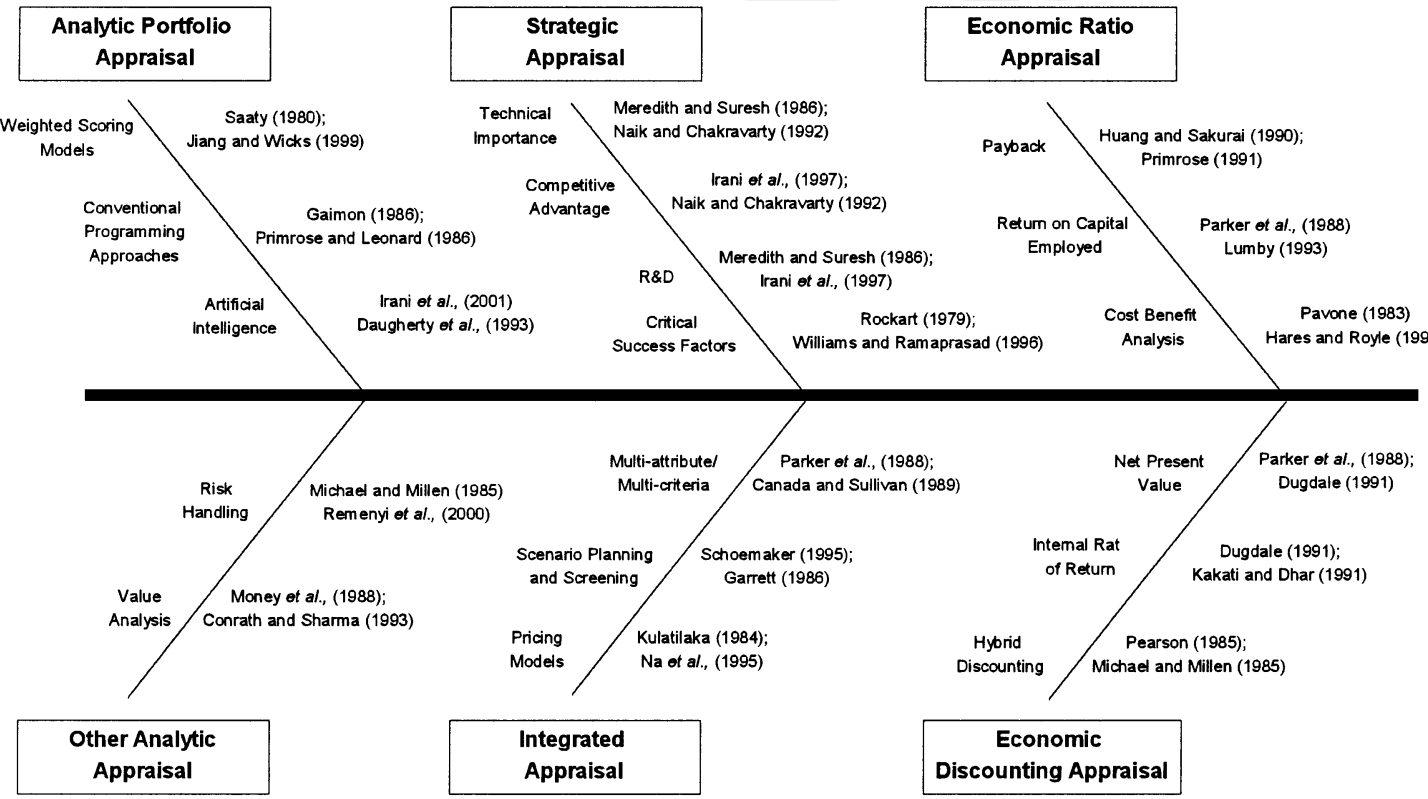

Figure 4 Taxonomy of investment appraisal techniques.

quantitative and qualitative implications, yet both are prone to subjectivity. These techniques acknowledge the impact of the project in the long-term (strategic), by assessing the alignment of the investment initiative to the business goals of the company. However, such techniques often ignore risk, time and economic factors.

Analytical approaches to investment appraisal are structured in nature but may be considered subjective, judgmental and complicated in application, with the same data often producing results. The uses of such techniques include the consideration of quantitative and qualitative factors. These methods may be able to acknowledge project or event risk. Further techniques within the analytic approach to investment appraisal, offer effective management tools for providing a wider perspective of the investment implications, through risk handling and value analysis.

Finally, integrated appraisal techniques combine subjectivity with structure. These techniques integrate financial, quantitative and qualitative aspects, through the assignment of weighting factors, to the intangible and non-financial implications of the project. Here again, project risk can be partially acknowledged, albeit subjectively.

\section{Conclusions}

The ex-ante evaluation of IS appears to be moving away from a process embedded within capital budgeting, to one that is now a matter of consumption. This shift is motivated in part by IS being seen as a necessity that is integral to the fabric of a company's infrastructure and success.

In considering IS planning levels and corresponding strategic, tactical and operational benefit levels, writers in the accounting stream of the literature are convinced that traditional capital budgeting is still valuable. Such views expect financial returns from the investment to play a key role in the decision-making process. There appears to be little controversy over this point, but the contentious issue is the degree of involvement financial appraisal should play and the predictive value that should be drawn from such conclusions during the ex-ante evaluation process. Conversely, the lack of widespread application of many strategic, analytical and integrated appraisal techniques (such as those presented in Figure 4), which would appear to partly address many of the described shortcomings, may be considered to be due to their complexity, subjectivity and high dependency on resource for selection and application. In considering this, the authors go some way to providing managers (at different levels in the organisation) with a deeper understanding and resulting rationale for navigating through the selection of investment appraisal techniques.

In this paper, a number of investment appraisal methods have been identified and classified, together with a discussion of the issues associated with their application. These methods have been presented in an appraisal taxonomy (Economic Ratio, Economic Discounting, Strategic, Analytic Portfolio Integrated and Other Analytic) that offers itself, as a frame of reference for decision-makers that are embracing IS evaluation.

Acknowledgements - The authors would like to express their gratitude to Professor Frank Land and Dr Barbara Farbey for their tremendous help and support during the development of this paper. The authors would like to also acknowledge the financial support provided by the Engineering and Physical Sciences Research Council (EPSRC) Grant Ref: [GR/M95066] and [GR/R08025]. <aq6>0 


\section{References}

ANANDARAian A and Wen HJ (1999) Evaluation of information technology investments. Management Decision 37(4), 329-337.

ANGELL IO and SMithson S (1991) Appraisal, monitoring and control In Information Systems Management: Opportunities and Risks, pp 189-212, Macmillan.

Anthony R (1965) Planning and Control Systems: A framework for analysis. Harvard University Graduate School of Business Administration, Cambridge, USA.

Anthony RN, DEARden J and BedFord N (1984) Management Control Systems Homewood, USA.

ARribas EH and INCHUSTA PJS (1999) Evaluation models of IT in Spanish companies: a cluster analysis. Information and Management 36(3), 151-164

$<$ AQI $>$ B Ballantine J and Stray S (1998) Financial appraisal and the IS/IT investment decision making process. The Journal of Information Technology 13(1), 3-14.

BANNISTER F and REMENYI D (2000) Acts of faith: instinct, value and IT investment decisions. Journal of Information Technology 15(3), 231-241

Butler R, Davies L, Pike R and Sharp J (1993) Strategic Investment Decisions: Theory, Practice and Process. Routledge, USA.

CANAda JR and Sullivan WG (1989) Evaluation of Advanced Manufacturing Systems. Prentice-Hall, USA.

Chen IJ and Small MH (1994) Implementing advanced manufacturing technology: an integrated planning model. International Journal of Management Science (Omega) 22(1), 91-103.

ConRath DW and Sharma RS (1993) Evaluation measures for computer-based information systems. Computers in Industry 21(3), 267-271.

Daugherty LC, PARSAei HR and Kolli SS (1993) Expert Systems for the Strategic Justification of Advanced Manufacturing Technology Systems. Proceedings of Industrial Engineering Research Conference, USA, pp 97-101.

Demmel JG and AsKIN RG (1992) A multiple-objective decision model for the evaluation of advanced manufacturing technologies Journal of Manufacturing Systems 11(3), 179-194.

Drummond H (1996) Escalation in Decision Making. Oxford University Press, London, UK

Dugdale D (1991) is there a correct method of investment appraisal Management Accounting 69(5), 46-50.

Dugdale D and Jones C (1995) Financial justification of advanced manufacturing technology. Issues in Management Accounting (Ashton D, Hopper T, Scapens RW Eds) pp 191-213. Prentice-Hall.

EZINGEARD J-N, IRANi Z and RACE P (1999) Assessing the value and cost implications of manufacturing information and data systems: an empirical study. European Journal of Information Systems 7(4), $252-260$

FARBEY B, LAND F and TARGETT D (1992) Evaluating Investments in IT/IS. Journal of Information Technology 7(2), 109-122.

FARBey B, LAND F and TARgett D (1993) IT Investment: A Study of Methods and Practices. Management Today and Butterworth-Heinemann Ltd, UK.

FARbey B, TARgetT D and LAND F (1994) Matching an IT project with an appropriate method of evaluation: a research note on evaluating IT. Journal of Information Technology 9(3), 239-243.

Gaimon C (1986) The strategic decision to acquire flexible technology. In Proceedings of the second ORSA/TIMS Conference on Flexible Manufacturing Systems: Operations Research Models and Applications (STECKe KE and SURI R Eds) pp 43-54 USA.

Garrett SE (1986) Strategy first: a case in FMS Justification. Proceedings of the 2nd ORSA/TIMS Conference on Flexible Manufacturing Systems: Operations Research Models and Applications (Stecke KE and Suri R Eds) pp 17-29 USA.

GuRNANI C (1984) Capital budgeting: theory and practice. The Engineering Economist 30(1), 19-46.

GiNZBERG MJ and ZMUD RW (1988) Evolving criteria for information systems assessment: In Information Systems Assessment: Issues and Challenges (Bjorn-Andersons N and Davis GB Eds) pp 41-52.

HARES J and Royle D (1994) Measuring the Value of Information Technology. John Wiley and Sons Ltd, UK.
HaRris S (1996) Human Communication and Information Systems. NCC Blackwell, UK

Hochstrasser B (1990) Evaluating IT investment-matching techniques to projects. Journal of Information Technology 5(4), 215221

Hochstrasser B (1992) Justifying IT investments. Proceedings of the Advanced Information Systems Conference; The New Technologies in Today's Business Environment pp 17-28, UK.

HuANG P and SAKurai M (1990) Factory automation: the Japanese experience. IEEE Transactions on Engineering Management 37(2), $102-108$.

IRANI Z, EZINGEARD J-N and GRIEVE RJ (1997a) Integrating the costs of an IT/IS infrastructure into the investment decision making process. The International Journal of Technological Innovation, Entrepreneurship and Technology Management (Technovation) 17(11/12), 695-706.

IrANi Z, SharP JM and RACE P (1997b) A case experience of new product introduction within a once traditional subcontract manufacturing environment. Production and Inventory Management Journal 38(2), 47-51.

Irani Z, EzINGEARD J-N and Grieve RJ (1998) Costing the true costs of IT/IS investments: a focus during management decision making. Journal of Logistics and Information Management 11(1), 38-43.

IRANI Z, LOVE PED and LI H (1999a) IT/IS investment barriers to the decision making process. Business Information Technology World (BITWorld 99) Conference, [CD Proceedings]. Cape Town, South Africa.

Irani Z, EzIngeard J-N, Grieve RJ and RaCe P (1999b) Investment justification of information technology in manufacturing. The International Journal of Computer Applications in Technology 12(2), 90-101.

IrANi Z, Sharif AM and Love PED (2001a) Transforming failure into success through organizational learning: an analysis of a Manufacturing Information System. European Journal of Information Systems 10(1), 55-66.

Irani Z, Sharif AM, Kahraman C and Love PED (2001b) Fuzzy cognitive mapping as a technique for justifying manufacturing investments in IT/IS: a conceptual application. The International Journal of Production Economics (in press)

IRANI Z and Love PED (2001) The propagation of technology management taxonomies for evaluating investments in information systems. Journal of Management Information System 17(3), 159-175.

JIANG K and WICKS EM (1999) An integrated investment justification approach for cellular manufacturing systems using activity-based costing and the analytic hierarchy process. Journal of Engineering Valuation and Cost Analysis 2(4), 271-284.

KAKATI M and DHAR U (1991) Investment justification of flexible manufacturing systems. Engineering Costs and Production Economics 21(3), 30-43.

Khalifa G, IrANi Z and BALdwin LP (1999) Factors impacting IT/IS investment adaption and exploitation: a conceptual model. Proceedings of the 6th European IT Evaluation Conference (Remenyi D, Irani Z and Brown A Eds) Brunel University, London, UK

KulatilaKa N (1984) Financial, economic and strategic issues concerning the decision to invest in advanced automation. International Journal of Production Research 22(6), 949-968.

LEFLEY F (1994) Capital investment appraisal of manufacturing technology. International Journal of Production Research 32(12), 2751-2756.

LEFLEY F and SARKIS J (1997) Short-termism and the appraisal of AMT capital projects in the US and UK. International Journal of Production Research 35(2), 341-355.

Love PED and IRANI Z (2001) Evaluating the costs of IT/IS in construction. Automation in Construction 10(6), 649-658.

Lumby S (1993) Investment Appraisal and Financial Decisions: A First Course in Financial Decision. Chapman and Hall, London, UK.

MASKELL B (1991) Performance Measurement for World Class Manufacturing: A Model for American Companies. Productivity Press, USA.

Meredith JR and Suresh NC (1986) Justification techniques for 
advanced technologies. International Journal of Production Research 24(5), 1043-1057.

Money A, Tromp D and Wegner G (1988) The quantification of decision support benefits within the context of value analysis. MIS Quarterly 12(2), 223-236.

Michael GJ and Millen RA (1985) Economic justification of modern computer-based factory automation equipment: a status report Operation Research 3(1), 25-34.

Na SL, Green CJ and Maggioni P (1995) Market imperfections and the capital asset pricing model: results from aggregate UK data. Oxford Economic Papers 47(3), 453-470.

NAIK B and ChaKravarTy AK (1992) Strategic acquisition of new manufacturing technology: a review and research framework. International Journal of Production Research 30(7), 1575-1601.

Parker MM, Benson RJ and Trainor HE (1988) Information Economics: Linking Business Performance to Information Technology. Prentice Hall, USA.

PARKER MM and BENSON RJ (1989) Enterprise-wide information economics: latest concepts. Journal of Information Systems Management 6(4), 7-13

PAvone VJ (1983) Methods for economic justification of an are welding robot installation. Welding Journal 62(11), 39-46.

PeARSON GJ (1985) The Strategic Discount. John Wiley, New York, USA.

PETERS G (1994) Evaluating your computer investment strategy. Infor mation Management: The Evaluation of Information Systems invest ments (Willcocks L Eds) pp 99-131, Chapman and Hall, London, UK.

Proctor MD and CANAdA JR (1992). Past and present methods of manufacturing investment: a review of the empirical and theoretical literature. Engineering Economist 38(1), 45-58.

Primrose PL and LeONARD R (1986) The financial evaluation and economic application of advanced manufacturing technology. Proceedings of the Institute of Mechanical Engineers 200B(1), 27-31.

Primrose PL (1991) Investment in Manufacturing Technology. Chapman and Hall, London, UK.

Remenyi D, Money A, Sherwood-Smith M and Irani Z (2000) The Effective Measurement and Management of IT Costs and Benefits. Butterworth Heinemann/Computer Weekly-Professional Information Systems Text Books series, 2nd edn, ISBN 075064420 6 , UK

\section{About the authors}

Dr Zahir Irani is a Senior Lecturer and the Director of Postgraduate studies in the Department of Information Systems and Computing, Brunel University (UK). Having worked for several years as a project manager, Zahir retains close links with industry, and is a non-executive director to a leading engineering company, and has acted as a consultant for organisations such as Royal Dutch Shell Petroleum, BMW (UK) and Adidas. Dr Irani reviews research proposals that are submitted to the European Union together with grant applications submitted to the National Science Foundation (NSF) in the USA. He serves as a non-executive member to an international academic advisory group for MCB University Press. He is also a member of the editorial board of Butterworth Heinemann/Computer Weekly_Professional Information Systems Text-Book series.

Dr Irani is the director of a multi-disciplinary research group investigating information systems evaluation and integration, where he supervises a number of PhD students. He is a Visiting Scholar to the University of Salford (UK), and a Visiting Professor at Deakin University (Australia). Dr Zahir Irani is the Editor-in-Chief of the established Journal of Logistics Information Management, and is the European editor of the Business Process Management Journal. He has co-authored a teaching textbook on information systems evaluation, and written over 100 internationally refereed papers and received ANBAR citations of research excellence. He has spoken at conferences
RENKEMA TJW and Berghout EW (1997) Methodologies for information-systems investment evaluation at the proposal stage-a comparative review. Information and Software Technology 39(1), 1-13.

RoCKART JF (1979) Chief executives define their own data needs. Harvard Business Review 57(2), 81-93.

SaAty TL (1980) The Analytical Hierarchy Process: Planning, Priority Setting, Resource Allocation. McGraw-Hill, New York, USA.

SCAPENS RW and SALES JR (1981) Performance measurement and formal capital expenditure controls in divosional companies. Journal of Business Finance and Accounting 8(3), 389-419.

SCHOEMAKER PJH (1995) Scenario planning: a tool for strategic thinking. Sloan Management Review 36(2), 25-40.

Serafeimidis V and Smithson S (2000) Interpretive IS evaluation in practice: experience from a case study. Journal of Information Technology 15(2), 93-105.

Slagmulder R, Bruggeman E and Wassenhove L-V (1995) An empirical study of capital budgeting practices for strategic investments in CIM technologies. International Journal of Production Economics 40(2-3), 121-152. manufacturing technology: an empirical analysis. Journal of Engineering and Technology Management 12(1-2), 27-55.

SMithSON S and HiRschHeIM RA (1998) Analysing information systems evaluation: another look at an old problem. European Journal of Information Systems 7(3), 158-174.

SundEM GL and GeIJSBECK WR (1978) Survey and analysis of capital budgeting methods. Journal of Finance 33(1), 281-287.

TAYYARI F and KROLL DE (1990) Total cost analysis of modern automated systems. Justification Methods for Integrated Manufacturing Systems (Parsaei H, Ward T and Karwoski W Eds) pp 234-241, Elsevier, USA.

Williams JJ and RAMAPRASAD A (1996) A taxonomy of critical success factors. European Journal of Information Systems 5(4), 250260

WORLD Information Technology and Services Alliance (2000) Digital Planet 2000: The Global Information Economy. http://www.witsa .org/

WYSOCKI RK and Young J (1989) Information Systems: Management principles in action. John Wiley, New York, USA.
SMALL MH and CHEN J (1995) Investment justification of advanced

and guest seminars worldwide. Dr Irani is on the editorial board of several journals, as well as having been a co-and-mini-track chair to international conferences. Dr Irani has received numerous grants and awards from national/international funding bodies that include the Engineering and Physical Sciences Research Council (EPSRC), Department of Trade and Industry (DTI), Royal Academy of Engineering, Australian Research Council (ARC), Defence Evaluation Research Agency (DERA) and the European Union. Further biographical detail can be found at: http://www.brunel.ac.uk/ csstzni

Professor Peter ED Love has co-authored three books, written over 150 internationally refereed journals and spoken at conferences worldwide in the areas of quality and IT/IS project management. Evidence of his work can be found in numerous international journals, such as: European Journal of Information Systems, Journal of Management Information Systems, International Journal of Production Economics, and International Journal of Information Management. In addition, he has guest edited special issue international journals on themes Multi-media Technology, Electronic and Internet Commerce and Supporting Supply Chains through IT/IS. Professor Love evaluates grant proposals submitted to the Engineering and Physical Sciences Research Council (EPSRC) in the UK. His research in the area of IT/IS has been recognised by the Department of Building and Real Estate at Hong Kong Polytechnic 
897 University, as he has been invited on several occasions to ${ }_{898}$ attend the department as a Visiting Professor. He also serves 899 on the Editorial Advisory Board of several international jour900 nals and conference scientific technical committees. He is cur901 rently the Asia-Pacific Editor for Logistics Information Man${ }_{9 \mathbf{2} 2}$ agement: an International Journal. 